\title{
The effects of water on the dielectric properties of silicon based nanocomposites
}

\author{
Ian L Hosier, Matthew Praeger, Alun S. Vaughan and Steve G Swingler
}

\begin{abstract}
A series of polyethylene-based nanocomposites was prepared, utilizing silicon nitride or silicon dioxide (silica) nanopowders, and the effect of filler loading and conditioning (i.e. water content) on their morphology and electrical properties was examined. The addition of nano-silicon nitride led to systems that were free of obvious nanoparticle aggregates, whereas the nanosilica based systems showed evidence of aggregation up to the micrometer-scale. While the nano-silicon nitride composites remained essentially dry under ambient conditions, the nanosilica-based composites absorbed appreciable quantities of water from the ambient environment, indicating that interactions with water are dependent on the nanoparticle surface chemistry. Dielectric spectroscopy showed a broad relaxation peak due to adsorbed water at nanoparticle surfaces, which shifted to higher frequencies with increased water content. Similarly, the electrical conductivity was found to be highly sensitive to the presence of absorbed water, particularly for systems containing well dispersed nanoparticles. We conclude that, in nanodielectric applications, nanoparticle surface chemistry is important in determining macroscopic properties, and not just as a means of compatibilizing the filler and the matrix. Additional factors can be critical, here, as exemplified by interactions with water.
\end{abstract}

Index Terms-Dielectric spectroscopy, electrical conductivity, nanocomposites, polyethylene, silica, silicon nitride.

\section{INTRODUCTION}

$\mathrm{N}$ ANOCOMPOSITES, where a nano-scale inorganic filler is incorporated into a polymeric host material, provide an effective means of enhancing the mechanical and dielectric properties of existing polymeric materials [1]. From an electrical perspective, the benefits include: improved partial discharge (PD) resistance [2]; improved treeing resistance [3] and improved flashover performance [4]. In many items of high voltage plant, polymers have largely superseded other insulation materials and, given that nano-silica is cheap and chemically inert, polymer/silica nanocomposites have been studied extensively. Many published papers [5-10] focus on

The authors gratefully acknowledge the RCUK's Energy Programme for the financial support of this work through the Top \& Tail Transformation programme grant, EP/I031707/1 (http://www.topandtail.org.uk/). All data published in this paper are openly available from the University of Southampton repository at $\mathrm{http} / / /$ doi.org/10.5258/SOTON/402211.

I. L. Hosier and M. Praeger both work as postdoctoral researchers within the Tony Davies High Voltage Laboratory (e-mail: ilh@ecs.soton.ac.uk; mattp@soton.ac.uk).

A. S. Vaughan is currently the head of the Electronics and Electrical Engineering group at the University of Southampton (E-mail: asv@ecs.soton.ac.uk).

S. G. Swingler (retired) was formally a Professor in the Electronics and Electrical Engineering group (E-mail: s.g.swingler@soton.ac.uk) epoxy-based systems and report improved mechanical and dielectric performance at low filler loadings. However, detrimental effects are seen at higher filler loading levels, which are often attributed to particle aggregation.

Achieving optimal nanoparticle dispersion and avoiding aggregation in polyethylene is challenging and, consequently, the literature presents a mixed picture. A comparison of the effects of micro and nano-scale fillers was provided by Roy et al. [11], where vinyl-silane treatment of the filler was used to modify the nanoparticle surface chemistry. Excellent particle dispersion was reported and, in the nanocomposites, the $\mathrm{AC}$ breakdown strength and voltage endurance were both improved and heterocharge accumulation was reduced. This work demonstrates that enhanced properties come about through modified chemical interactions between the filler and the host polymer, leading to improved nanoparticle dispersion, together with changes in the nature of the nanofiller/matrix interface. A later paper [12] suggests that the type of surface treatment agent has only a minor role in determining the dielectric properties of the composite systems, rather consumption of surface hydroxyl groups is key.

Polyethylene-based nanocomposites containing unfunctionalized silica were compared to those functionalized with trimethoxy(propyl)silane by Lau et al. [13, 14]. Morphological studies [13] revealed good dispersion at low filler loadings but particle aggregation at high filler loadings. Accumulated homocharge was exaggerated in the nanocomposites, particularly when the nano-filler was unfunctionalized [14], and the DC breakdown strength was reduced in the nanocomposites compared to the unfilled reference material. In addition, this work also considered a further factor, namely, the potential effect of mobile moieties adsorbed on nanoparticle surfaces. Starting from dried samples, water uptake measurements showed negligible water uptake in the unfilled polyethylene, but a maximum water uptake of $1.6 \%$ and $0.7 \%$ in nanocomposites containing unfunctionalized and functionalized silica respectively at a filler loading level of $10 \mathrm{wt}$. \%. Dielectric properties were found to be critically dependent upon water content, with absorbed water resulting in increased permittivity and dielectric loss peaks being displaced to higher frequencies. Hui et al. [15] considered water absorption in nanocomposites based on crosslinked polyethylene (XLPE), reporting the absorption of up to $1.5 \%$ of absorbed water, regardless of the state of functionalization. While dry samples did not exhibit much increase in dielectric loss, wet samples showed a mid- 
frequency relaxation feature. Space charge behavior switched from homocharge to heterocharge in moving from dried to wet samples and the AC breakdown strength was reduced. Finally, Zhang et al. [16] reported improved DC breakdown strength in a series of nano-silica/XLPE nanocomposites, which showed good dispersion when the nano-filler was functionalized.

In polyester-based systems [17], an increase in permittivity at low frequencies $(<300 \mathrm{~Hz})$ was observed, which was attributed to an increase of ion mobility and the MaxwellWagner effect, along with an additional mid-frequency loss feature $\left(\sim 10^{4} \mathrm{~Hz}\right)$. This relaxation process was pronounced for filler loadings $>6 \%$, where particle aggregation was observed. In another study [18] colloidal nano-silica was used to give good particle dispersion and it was noted that the permittivity and dielectric loss increased in the nanocomposites, relative to the unfilled host polymer, but in some systems the dielectric breakdown strength could be improved. Polypropylene (PP) systems containing an impact modifier (SEBS) plus maleic anhydride grafted PP have also been studied [19]. Whilst the presence of SEBS resulted in a relaxation peak at $\sim 1 \mathrm{~Hz}$ (attributed to the $\alpha$ relaxation and interfacial polarization), addition of the nano-silica led to a broad dispersion at $100 \mathrm{~Hz}$. Such results where a broad midfrequency relaxation feature is observed are common in the literature over a range of thermoplastic host materials. The relaxation is shifted to higher frequencies with higher temperatures [19] or with increasing water uptake [14, 15, 20] and is usually attributed to loosely bound water clusters at nano-silica/polymer interfaces [13, 15, 19-21].

To summarize, whilst the situation in epoxy based nanocomposites is fairly clear, in that improved electrical performance is possible with a low nano-filler loading, inconsistent results are reported for thermoplastic hosts. From the above review, it would appear that the origins of such variability are twofold. First, there are variations in the level of particle dispersion - where morphological data were provided, poor particle dispersion always resulted in reduced breakdown strength $[14,21,22]$. In contrast, improved dispersion (obtained, for example, from sol-gel or masterbatch compounding) resulted in either improved breakdown performance $[10,11,16]$ or no change [7]. Second, variations in water content appear to be of great importance - the few studies that have considered this suggest that water absorption always leads to reduced breakdown strength $[15,22]$, increased dielectric loss $[5,13,15,22]$ and a switch in the space charge behavior from homocharge to heterocharge [15]. It would therefore appear important to eliminate adsorption of water at nanoparticle interfaces, through appropriate drying and/or through the removal of surface hydroxyl groups that can lead to hydrogen bonding with water molecules $[1,2,15]$.

The use of nitride nano-fillers in place of oxides will change the basic nanoparticle surface chemistry and, in the extreme case, effectively eliminate surface hydroxyl groups. However, in practice, this tends not be the case - the surface of silicon nitride, for example, has been shown to oxidize in air at room temperature to produce an oxynitride layer [23]. Nevertheless, this provides a distinct surface chemistry which would be expected to influence water uptake. Silicon nitride also exhibits excellent thermal conductivity [24] (which could be advantageous in terms of heat dissipation in technological applications) and could potentially lead to improved electrical breakdown performance [25]. Despite this, to our knowledge, no comparative study of the dielectric properties of nanocomposites based upon nano-silicon oxide and nanosilicon nitride has been carried out - this is the purpose of the investigation reported here.

\section{EXPERIMENTAL}

\section{A. Materials and blending}

Nano-silica (10-20 nm) and nano-silicon nitride (spherical $\sim 50 \mathrm{~nm}$ ) were obtained from Sigma Aldrich. Two filler concentrations were chosen; 5 and $10 \mathrm{wt}$. $\%$, to provide (a) a low level of filler, where dispersion problems are not reported in the literature and (b) a higher level where particle aggregation is frequently reported $[4,6,9,10,13,17]$.

A blend of $20 \mathrm{wt} . \%$ high density polyethylene (HDPE, BP Rigidex HD5813EA) and 80 wt. \% low density polyethylene (LDPE, ExxonMobil, LD100BW) was used as the polymeric host. This was prepared by melt mixing in a Polylab twin screw mixer $\left(160^{\circ} \mathrm{C}\right.$, speed 40 revolutions per minute (RPM), measured torque $8-12 \mathrm{~N} \mathrm{~m}$ ) for $20 \mathrm{~min}$.

The conventional solvent blending method for nanocomposites utilizes xylene as solvent and methanol as non-solvent $[13,22]$. Due to the non-polar nature of xylene it is difficult to obtain a stable suspension of nanofiller even after sonication and there are also concerns that precipitation into methanol (a polar solvent) might introduce unwanted aggregation or loss of filler. To overcome these difficulties, a modified solvent-based sample preparation method was used here. In this, $5 \mathrm{~g}$ of the polymer blend was dissolved in $50 \mathrm{ml}$ of boiling xylene and, in parallel, either 0.25 or $0.5 \mathrm{~g}$ of the required nano-powder was dispersed in $10 \mathrm{ml}$ of isopropyl alcohol (IPA), sonicated for 5 min using a Hielscher UP200S probe sonicator, stirred and sonicated for a further $5 \mathrm{~min}$. The xylene/polymer solution was removed from the heat, allowed to gel slightly and the nano-powder/IPA was immediately added (the small amount of IPA used here does not induce precipitation of the polymer). Stirring was maintained until the mixture had thickened to a waxy solid, which was then dried for $24 \mathrm{~h}$ in a fume cupboard, cut into $\sim 5 \mathrm{~mm}$ cubes and left for a further $24 \mathrm{~h}$. The product was pressed into sheets $2 \mathrm{~mm}$ in thickness at $160{ }^{\circ} \mathrm{C}$, in order to remove any solvent residues and included air bubbles. Five systems were prepared (Table I), two using nano-silica, two using silicon nitride plus an unfilled control.

TABLE I

BLENDS USED IN THESE INVESTIGATIONS

\begin{tabular}{|c|c|c|}
\hline Blend & Base resin & Nano-filler used \\
\hline Control & $20 \% \mathrm{HDPE} / 80 \% \mathrm{LDPE}$ & - \\
\hline SiN05 & $20 \%$ HDPE $/ 80 \%$ LDPE & 5 wt. $\%$ silicon nitride $\left(\mathrm{Si}_{3} \mathrm{~N}_{4}\right)$ \\
\hline SiN10 & $20 \%$ HDPE $/ 80 \%$ LDPE & 10 wt. $\%$ silicon nitride $\left(\mathrm{Si}_{3} \mathrm{~N}_{4}\right)$ \\
\hline $\mathrm{SiO} 05$ & $20 \%$ HDPE $/ 80 \%$ LDPE & 5 wt. $\%$ silica $\left(\mathrm{SiO}_{2}\right)$ \\
\hline $\mathrm{SiO} 10$ & $20 \%$ HDPE/ $80 \%$ LDPE & 10 wt. \% silica $\left(\mathrm{SiO}_{2}\right)$ \\
\hline
\end{tabular}




\section{B. Specimen preparation and conditioning}

Samples of the required thickness were produced using appropriate Melinex spacers in a hydraulic press $\left(160{ }^{\circ} \mathrm{C}\right.$ and 3 ton load). All samples were crystallized from the melt in oil baths maintained at $115{ }^{\circ} \mathrm{C}$ for $1 \mathrm{~h}$ prior to quenching into water $[13,14]$. These specimens were then conditioned to vary their water content as follows: "ambient" samples were maintained in the air conditioned laboratory environment $\left(19 \pm 2{ }^{\circ} \mathrm{C}, 55-80 \% \mathrm{RH}\right)$ for at least $14 \mathrm{~d}$ prior to testing; "dry" samples were then vacuum dried at room temperature for periods of up to $14 \mathrm{~d}$; "wet" samples were, after reaching equilibrium in the laboratory, immersed in water for periods of up to $14 \mathrm{~d}$. The sample mass was determined periodically during vacuum drying or water immersion (accuracy \pm $0.0001 \mathrm{~g}$ or $\pm 0.02 \%$ for a typical $0.5 \mathrm{~g}$ sample).

\section{Physical characterization}

Nano-powder was sprinkled onto adhesive carbon tape attached to carbon scanning electron microscope (SEM) stubs in order to provide samples for energy dispersive X-ray spectroscopy (EDS). These were examined in a Philips XL30 SEM operating at $10 \mathrm{kV}$. At least four spectra were acquired over an area of $50 \mu \mathrm{m}^{2}$ and averaged, ensuring that they did not contain any areas where the carbon tape was exposed. The $\mathrm{K} \alpha$ emission peaks of $\mathrm{Si}(1.74 \mathrm{keV}), \mathrm{O}(0.52 \mathrm{keV}), \mathrm{N}$ $(0.39 \mathrm{keV})$ and $\mathrm{C}(0.28 \mathrm{keV})$ were used to estimate the relative concentrations of each element. Thermogravimetric analysis (TGA) was performed by heating $5 \mathrm{mg}$ samples in a Perkin Elmer Pyris $1 \mathrm{TGA}$ at a rate of $20 \mathrm{~K} / \mathrm{min}$ in air.

Samples for morphological studies were etched for $4 \mathrm{~h}$ in a solution of $1 \mathrm{wt} . \%$ potassium permanganate in an acid mixture (5:2:1 of sulphuric acid, phosphoric acid and water respectively) [26], before being recovered, rinsed twice with distilled water and once with acetone and left to dry overnight. Samples were then mounted onto aluminium SEM stubs, gold coated and examined at $15 \mathrm{kV}$ in a JEOL JSM6500F high resolution field emission gun SEM (FEG-SEM).

Differential scanning calorimetry (DSC) was performed on $5 \mathrm{mg}$ samples, using a Perkin Elmer DSC-7, which was calibrated using high purity indium. Melting scans were obtained by heating at $10 \mathrm{~K} / \mathrm{min}$, while crystallization was examined by cooling at $5 \mathrm{~K} / \mathrm{min}$ from the melt. DSC was also used to verify blend uniformity after melt mixing.

Dielectric data were obtained from film samples $0.2 \mathrm{~mm}$ in thickness. Gold electrodes were sputtered onto the sample and data were acquired using a parallel plate test cell incorporating a guard ring electrode (diameter of inner electrode $30 \mathrm{~mm}$ ). Measurements of complex permittivity were performed using a Solartron 1296 dielectric interface linked to a Schlumberger SI 1260 impedance-gain-phase analyzer. A $1 \mathrm{~V}_{\mathrm{rms}} \mathrm{AC}$ signal was applied over a frequency range from $0.1 \mathrm{~Hz}$ to $1 \mathrm{MHz}$; all dielectric measurements were conducted at room temperature.

Measurements of electrical conductivity were performed at room temperature on the same (coated) samples placed between opposing $20 \mathrm{~mm}$ diameter polished gold coated electrodes. A stepped voltage $(100 \mathrm{~V}$ to $6 \mathrm{kV}$ in steps of
TABLE II

RESULTS FROM EDX ANALYSIS OF THE NANO-FILLERS (UNCERTAINTY $\pm 3 \%$ )

\begin{tabular}{l|c|c|c}
\hline \hline \multicolumn{1}{c|}{ Powder } & Silicon (\%) & Oxygen (\%) & Nitrogen (\%) \\
\hline Silica & 39 & 61 & $<1$ \\
Silicon nitride & 46 & 11 & 43 \\
\hline \hline
\end{tabular}

$100 \mathrm{~V}$ ) was applied and, for each data point, a waiting time of $10 \mathrm{~s}$ after application of the voltage was allowed before measuring the current, to allow capacitive currents to dissipate.

\section{RESULTS}

\section{A. Composition and Structure}

The nominal chemical compositions of the two nanofillers used in this work are shown in Table II, as revealed by EDS. The nano-silica $\left(\mathrm{SiO}_{2}\right)$ contains close to the expected 1:2 ratio of silicon to oxygen, while the nano-silicon nitride $\left(\mathrm{Si}_{3} \mathrm{~N}_{4}\right)$ has a 1:1 ratio of silicon to nitrogen rather than the expected 3:4 ratio. The detection of $\sim 10 \%$ of oxygen in place of nitrogen in this compound is consistent with the existence of an oxynitride surface layer with an approximate ratio of oxygen to nitrogen of about 1:3 which is not unreasonable [23].

Fig. 1 shows TGA decomposition curves, obtained from all five of the systems considered here after ambient conditioning. From this, the control sample (dotted line) starts to degrade at $300{ }^{\circ} \mathrm{C}$, reaching $50 \%$ of its initial mass at $410{ }^{\circ} \mathrm{C}$ and zero mass at $570{ }^{\circ} \mathrm{C}$. While SiN05 and SiN10 do not lose any mass in the temperature range $100-250^{\circ} \mathrm{C}, \mathrm{SiO} 05$ and $\mathrm{SiO} 10$ respectively lose 0.7 wt. \% and $1.2 \%$ of their initial mass below $280{ }^{\circ} \mathrm{C}$ (arrowed, inset, Fig. 1). These results suggest that while the silicon nitride contains negligible adsorbed water, the water content of the as supplied nano-silica is $\sim 10$ $\%$. Both SiN05 and SiO05 reach $50 \%$ of their initial mass at $\sim 420{ }^{\circ} \mathrm{C}$ whereas $\mathrm{SiN} 10$ and $\mathrm{SiO} 10$ reach the same point at $\sim 440^{\circ} \mathrm{C}$, indicating that both nano-fillers serve to enhance the thermal stability of the system. The final residue content at $570{ }^{\circ} \mathrm{C}$ is in all cases, within $1 \%$ of the expected value.

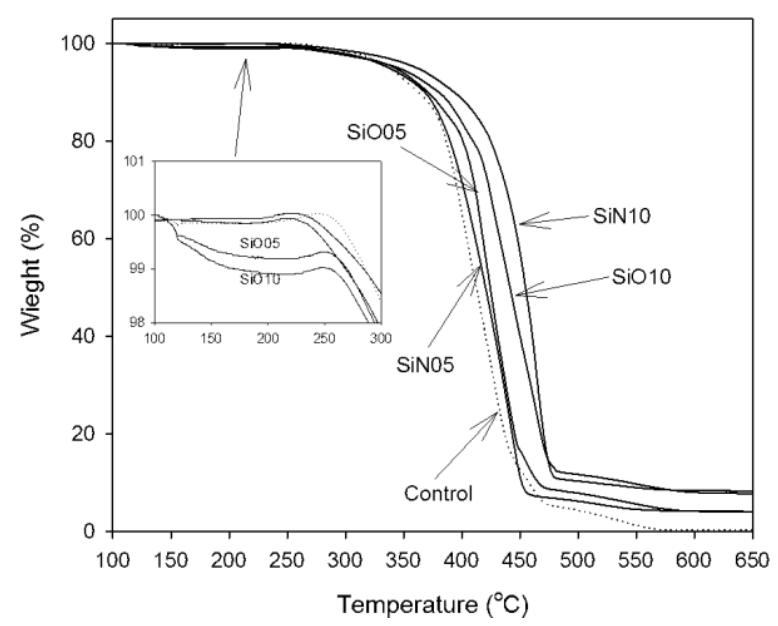

Fig. 1. TGA curves from all five nanocomposites considered here. All specimens were kept in equilibrium with the laboratory environment. 
SEM micrographs obtained from representative specimens are shown in Figs. 2 and 3. The control sample (Fig. 2a) exhibits a morphology based on banded spherulites, 10-20 $\mu \mathrm{m}$ in diameter, in accordance with published work [13, 14, 22]. In contrast, examination of both silicon nitride based systems, irrespective of filler loading level, reveals a disrupted polymeric texture containing a uniform distribution of submicron sized agglomerates (Fig. 2b) which are in turn composed of the expected $\sim 50 \mathrm{~nm}$ nanoparticles (Fig. $2 \mathrm{c}$ ).
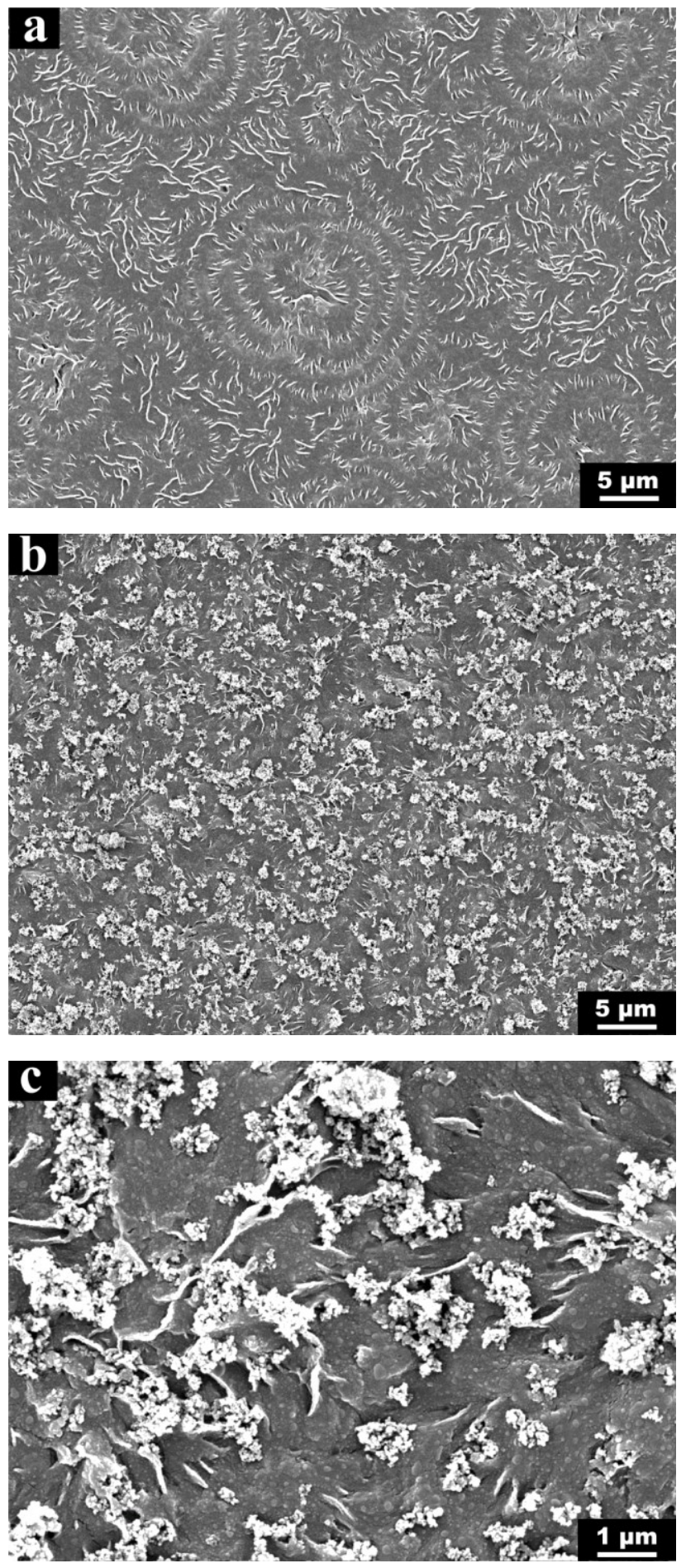

Fig. 2. SEM micrographs showing (a) the unfilled control, (b) SiN10, (c) details of SiN10.
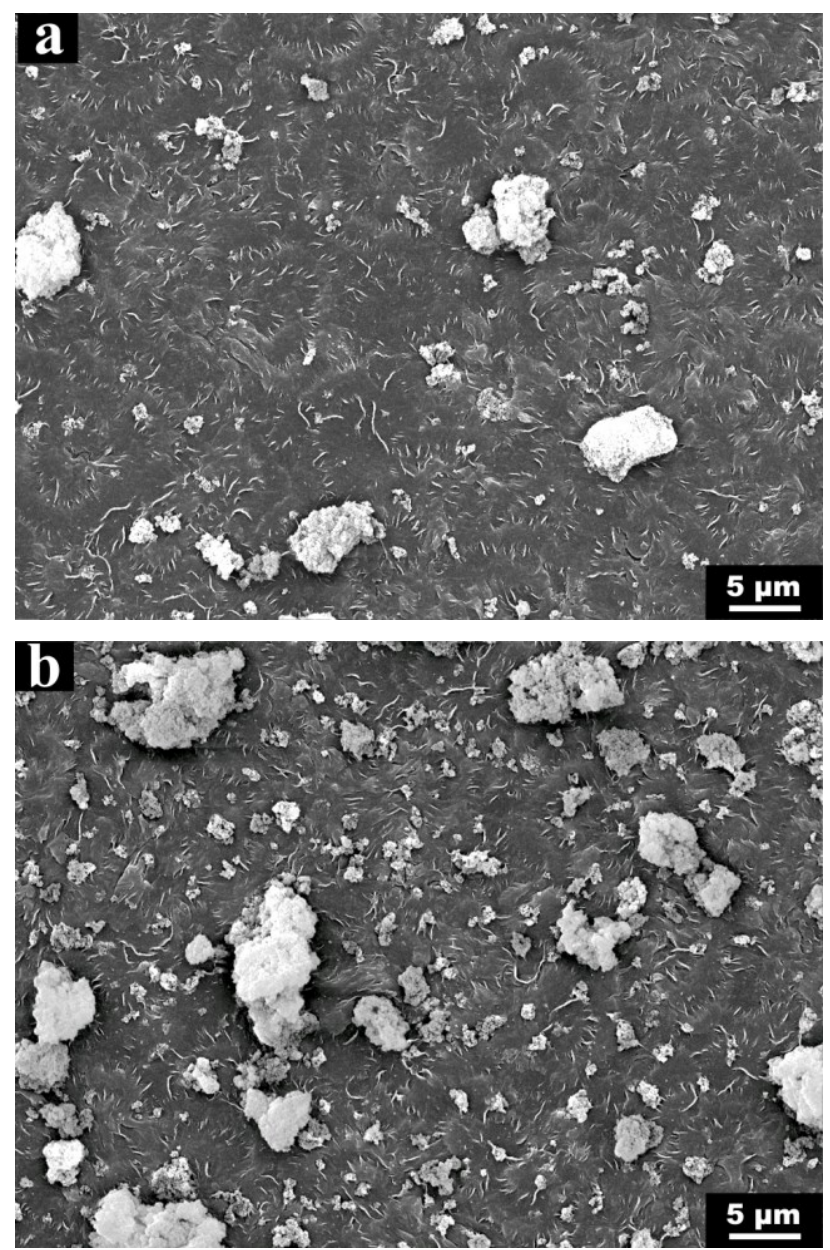

Fig. 3. SEM micrographs showing (a) $\mathrm{SiO} 05$, (b) $\mathrm{SiO} 10$

Whilst both silica nanocomposites (Fig. 3) show a large number of sub-micron sized particles, aggregates of up to 10 $\mu \mathrm{m}$ nevertheless persist, particularly in SiO10 (Fig. 3b), as observed in previous studies of materials based on this nanofiller [13, 14, 22]. Direct SEM examination of the nano-silica powder confirmed the presence of such aggregates. These structures are therefore neither introduced during blending nor totally removed by sonication and, the observed aggregation in the blends largely reflects the nature of the starting nanopowder.

Fig. 4 (top) shows five DSC melting traces, from which it is evident that all of the systems display two melting peaks, at 105 and $124{ }^{\circ} \mathrm{C}$ (LDPE and HDPE respectively) [22]. The total enthalpy is $\sim 110 \mathrm{~J} / \mathrm{g}$ for the unfilled control sample, falling in the nanocomposites to $\sim 100 \mathrm{~J} / \mathrm{g}$, due to the proportion of included filler. On cooling at $5^{\circ} \mathrm{C} / \mathrm{min}$ (Fig. 4, bottom set of traces) the control sample displays two peaks at 110 and $95^{\circ} \mathrm{C}$ (HDPE and LDPE respectively). Whilst the lower (LDPE) peak is located at the same temperature in the nanocomposites, crystallization of the HDPE occurs earlier at $\sim 112{ }^{\circ} \mathrm{C}$, which indicates that both nano-fillers serve to nucleate the HDPE component of the blend [19, 22, 27], such that the well-developed spherulitic architecture of the unfilled control sample is unable to develop in any of the nanocomposites. 


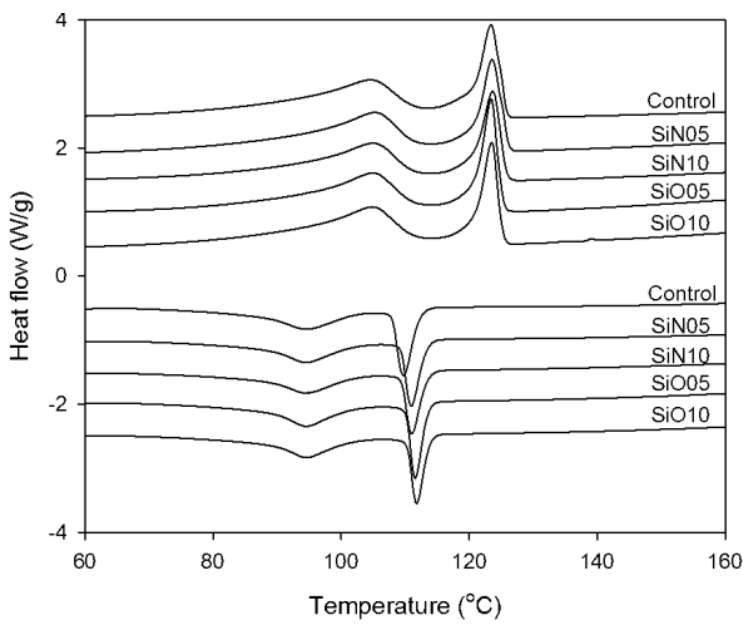

Fig. 4. DSC curves from melting (top) and recrystallization (bottom), curves displaced for clarity.

\section{B. Nanocomposite dielectric response}

Fig. 5 shows the frequency dependence of the real and imaginary parts of the relative permittivity of all formulations, when in equilibrium with the laboratory environment. For the control sample, the real, $\varepsilon^{\prime}$, and imaginary, $\varepsilon$ ", parts of the relative permittivity are 2.5 and $<5 \times 10^{-3}$ respectively. In
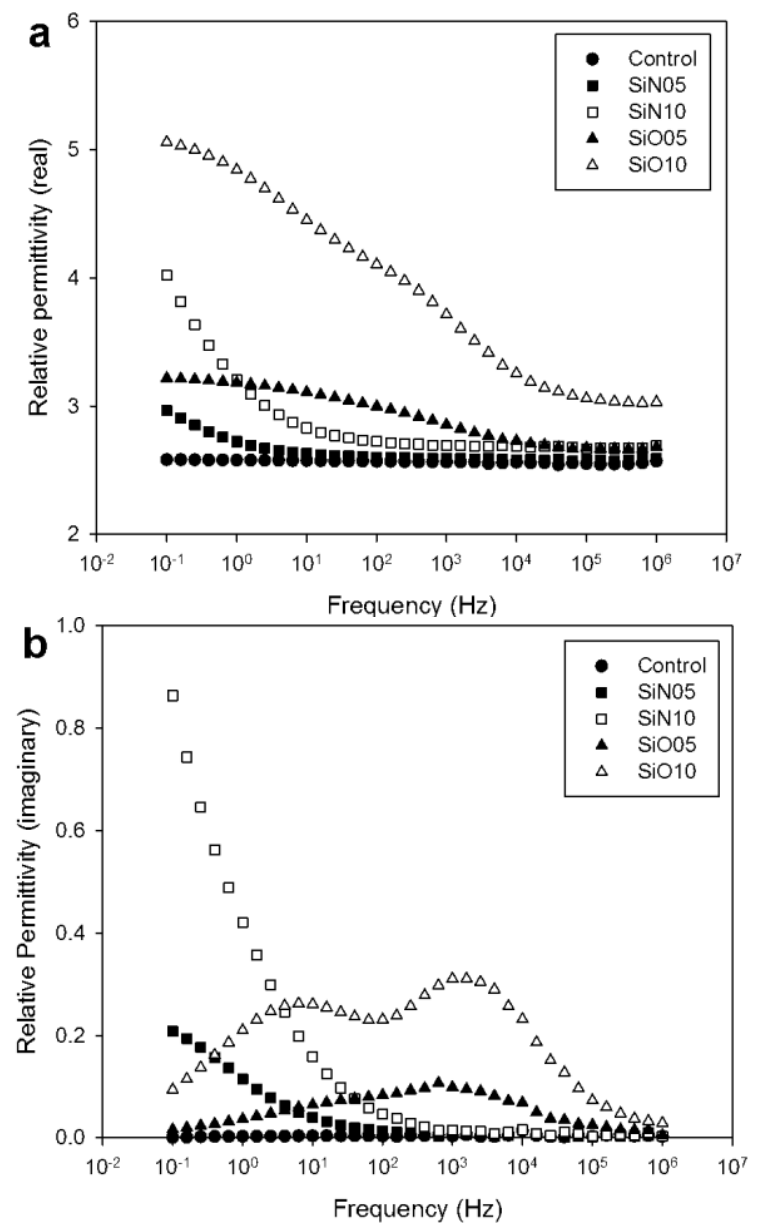

Fig. 5. Dielectric response from samples in equilibrium with the ambient laboratory environment: (a) real part of the relative permittivity, (b) imaginary part of the relative permittivity. contrast, both nano-silicon nitride-based composites show an increase in both $\varepsilon^{\prime}$ and $\varepsilon$ " at low frequencies - the increase in $\varepsilon$ " in SiN10 is particularly marked. Conversely, both nanosilica-based nanocomposites are characterized by lower loses at $10^{-1} \mathrm{~Hz}$ combined with broad relaxation features that are located at higher frequencies. In $\mathrm{SiO} 10$, for example, two distinct relaxation peaks can be seen in the imaginary permittivity (Fig. 5b), one at $\sim 10 \mathrm{~Hz}$ and a stronger feature at $\sim 2 \mathrm{kHz}$. Comparison of the nanocomposite data with those obtained from the unfilled reference indicates that all the relaxation processes seen in the nanocomposites are associated with the addition of the nano-filler.

The behavior seen in the nano-silicon nitride-based systems is consistent with published work, where low frequency relaxation processes are usually attributed to interfacial polarization [15, 17]. Specifically, interfacial dipoles related to a low concentration of tightly bound water molecules at nanoparticle interfaces $[1,2,15]$, which is entirely consistent with the notion of a surface oxynitride layer containing relatively few surface hydroxyl groups [23].

In the case of the nano-silica-based systems, comparable multi-modal mid frequency relaxation features have been widely reported $[5,8,11-13,15,17-20,22]$ and, again, are attributed to water absorbed at nanoparticle interfaces. However, in this case, the additional higher frequency feature indicates that at least some of the adsorbed water is present in loosely bound clusters and, is hence, more easily removed, as evinced by Fig. 1. To summarize, the observed dielectric response would appear to be strongly influenced by the presence of water molecules and, consequently, this issue was explored further.

\section{Kinetics of Water Absorption and Desorption}

Fig. 6 presents data obtained by immersing samples in water or storing in vacuum. At zero time, all specimens were in equilibrium with the laboratory environment and, in these plots, the change of mass on conditioning is presented as a percentage change relative to the initial sample mass. From this, it is evident that the mass of the unfilled control sample is

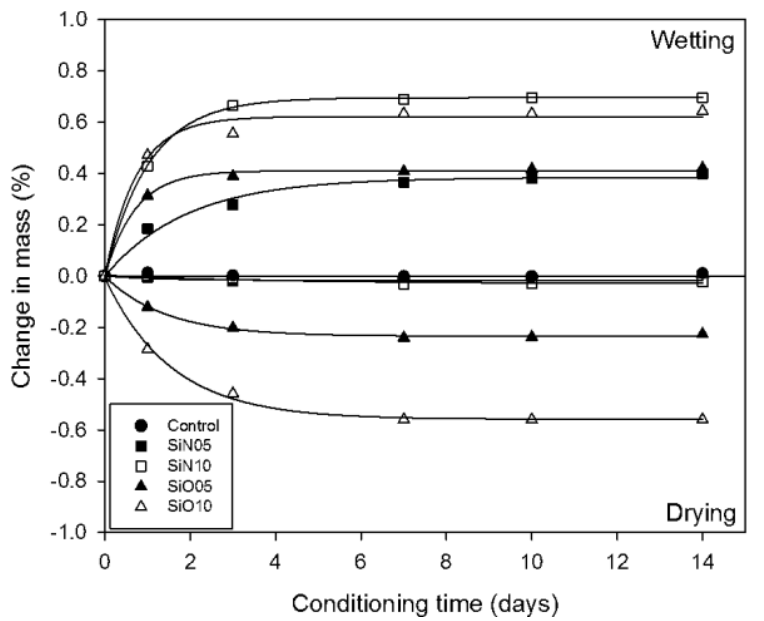

Fig. 6. Water absorption/desorption data. All changes in sample mass are relative to the initial mass of the specimen, in equilibrium with the ambient laboratory environment 
unaffected by either immersion in water or storage in vacuum, whereas the various nanocomposites reach a constant mass after about $7 \mathrm{~d}$ in either environment (water or vacuum). Neither SiN05 nor SiN10 loses significant mass during vacuum drying, suggesting that these systems absorb little water under ambient conditions, which is in line with the dielectric data presented above. However, on immersion in water, these systems are capable of absorbing up to $0.7 \%$ of the initial sample mass of water. It has been shown [23] that, in the presence of water, silicon nitride can further oxidize, leading to an increase in the number of surface hydroxyl groups and, hence, increased water adsorption. In contrast, the nano-silica-based systems are capable of losing or gaining water relative to the ambient state. The loss on vacuum storage of $\sim 0.2 \%$ and $\sim 0.6 \%$ of the initial sample mass of SiO05 and $\mathrm{SiO} 10$ respectively confirms the interpretation of Fig. 5 presented above and shows that, unlike SiN05 and SiN10, $\mathrm{SiO} 05$ and $\mathrm{SiO} 10$ both absorb a significant mass of water when stored under ambient conditions. The difference in water content between the $14 \mathrm{~d}$ vacuum dried and $14 \mathrm{~d}$ water immersed samples of $\mathrm{SiO} 10$ is $\sim 1.1 \%$, which is comparable with published data $[13,15,22]$.
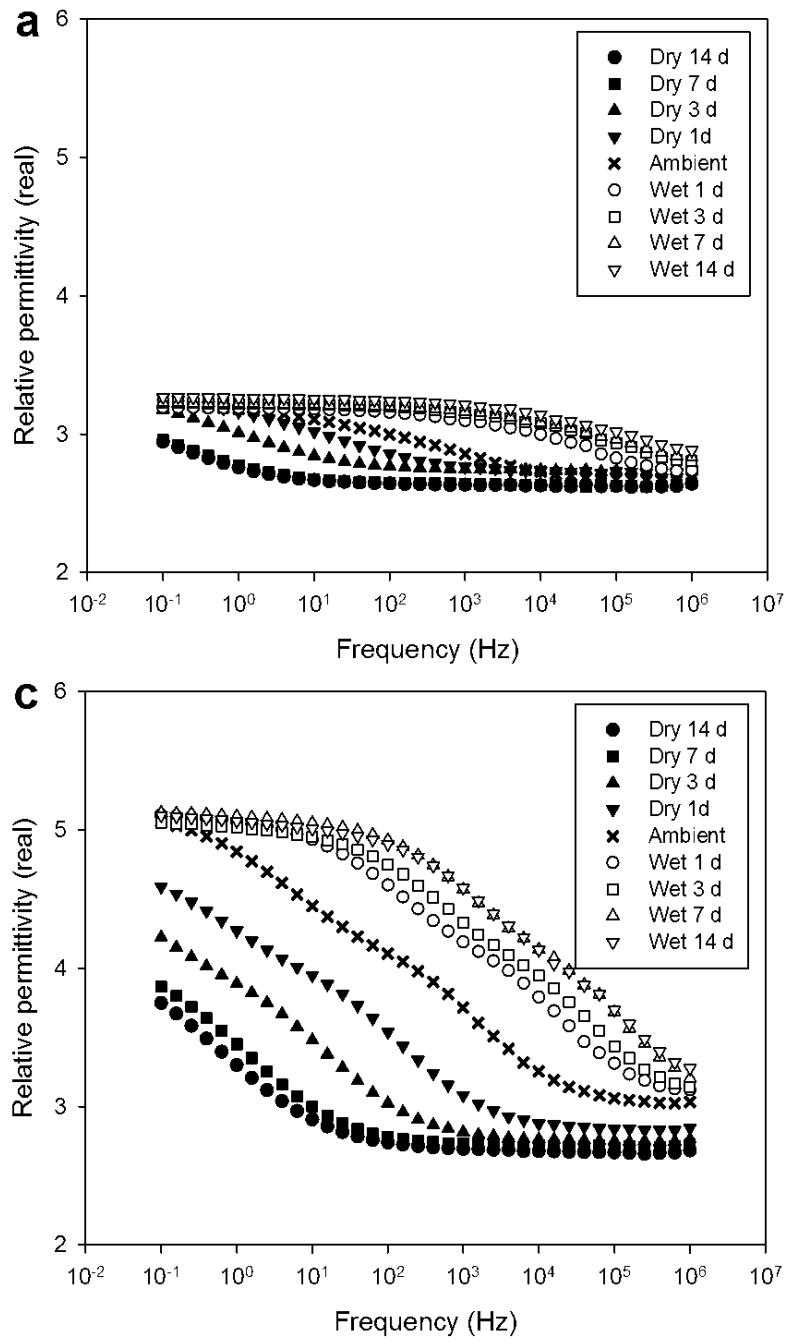

\section{Water Content and Dielectric Response}

It is evident from Fig. 6 that sample conditioning under vacuum, ambient conditions or immersion in water can be used to vary the water content of the nanocomposites considered here and that systems based upon nano-silica and nano-silicon nitride respond very differently to being conditioned.

Fig. 7 presents real and imaginary permittivity data obtained from $\mathrm{SiO} 05$ and $\mathrm{SiO} 10$ as a function of conditioning (i.e. water content). The behavior with increasing water content is consistent with comparable published data for silica-based nanocomposites $[13,15,22]$ and is related to increased mobility of the water moieties as the water content increases. In both $\mathrm{SiO} 05$ and $\mathrm{SiO} 10$ it is noteworthy that, even after $14 \mathrm{~d}$ in vacuum, these dielectric data reveal evidence of a low frequency process that manifests itself most clearly in Figs. 7a and $7 \mathrm{c}$ as an increase in $\varepsilon^{\prime}$ below about $1 \mathrm{~Hz}$. It would therefore appear that, in nano-silica based systems, a significant hydration layer remains even after vacuum drying at room temperature.

Fig. 8 shows equivalent dielectric data obtained from SiN05 and SiN10. In SiN05 (Fig. 8a), drying for $>3 \mathrm{~d}$ is sufficient to
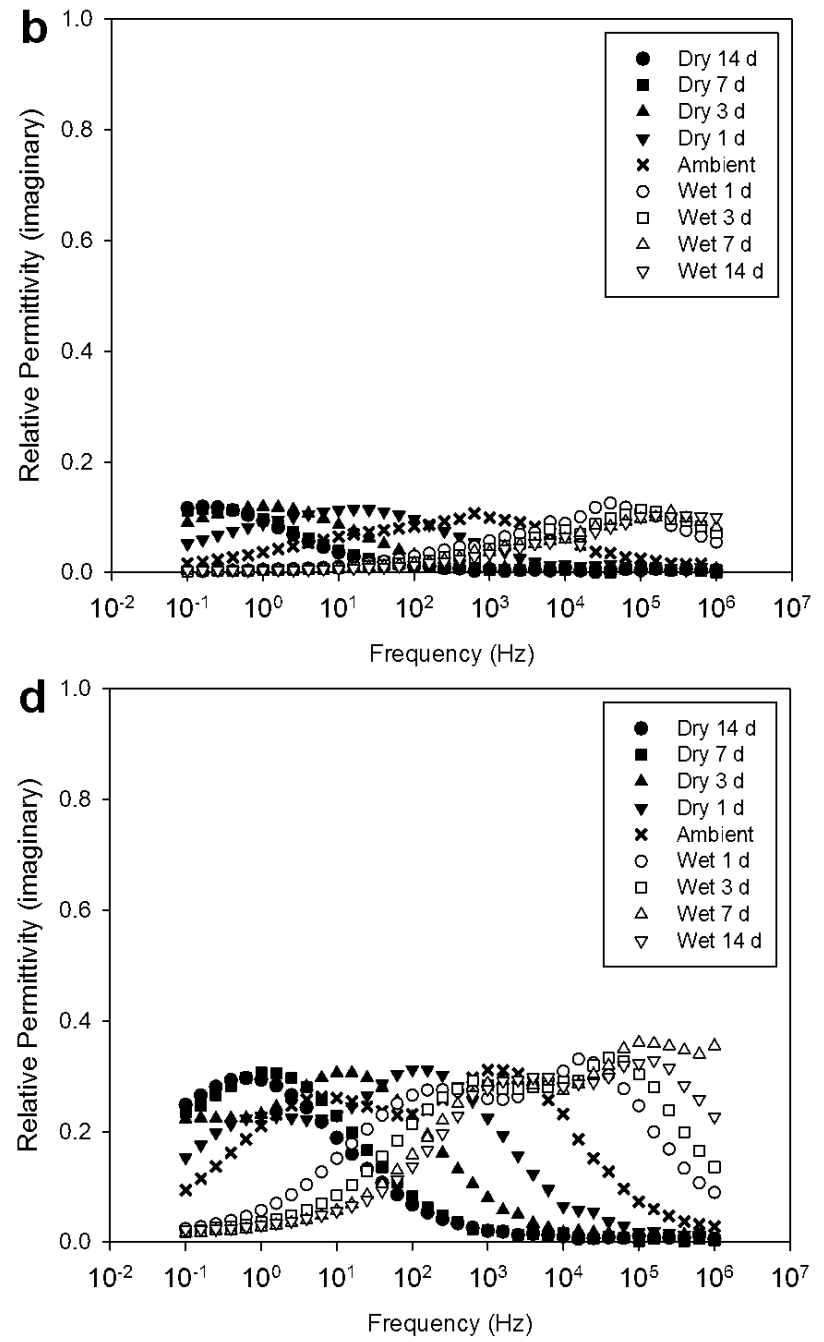

Fig. 7. Permittivity measurements; (a) SiO05 real (b) SiO05 imaginary, (c) SiO10 real, (d) SiO10, imaginary. 
remove contributions to the permittivity that are associated with the inclusion of the nano-filler, such that the real part of the relative permittivity, $\varepsilon^{\prime}$, is indistinguishable from that of the host polymer $(\sim 2.5)$ across the complete frequency range considered here. Conversely, immersion in water increases the real permittivity to a maximum value of $\sim 4.3$ (below $100 \mathrm{~Hz}$ from Fig. 8a) and the associated relaxation peaks in the imaginary permittivity shift to higher frequencies with increasing water immersion time (Fig. 8b). This displacement of the relaxation peak to higher frequencies with increasing water content mirrors the general effects shown in Fig. 7 and, consequently, we similarly associate this with increasing mobility of water moieties adsorbed at nanoparticle surfaces $[13,15,22]$. Figs. $8 \mathrm{c}$ and $8 \mathrm{~d}$ show dielectric data obtained from SiN10, but due to the wide variations seen in both $\varepsilon^{\prime}$ and $\varepsilon "$, these quantities are plotted on logarithmic scales. Comparison of the imaginary permittivity data shown in Fig. 8d with those shown in Fig. 8b reveals that a significant imaginary component remains in the former case $(\varepsilon " \approx 0.1$ at $10^{-1} \mathrm{~Hz}$ ) even after $14 \mathrm{~d}$ in vacuum, suggesting that, in SiN10, either the hydration layer cannot be completely removed by vacuum drying [15] or that such features are in some other
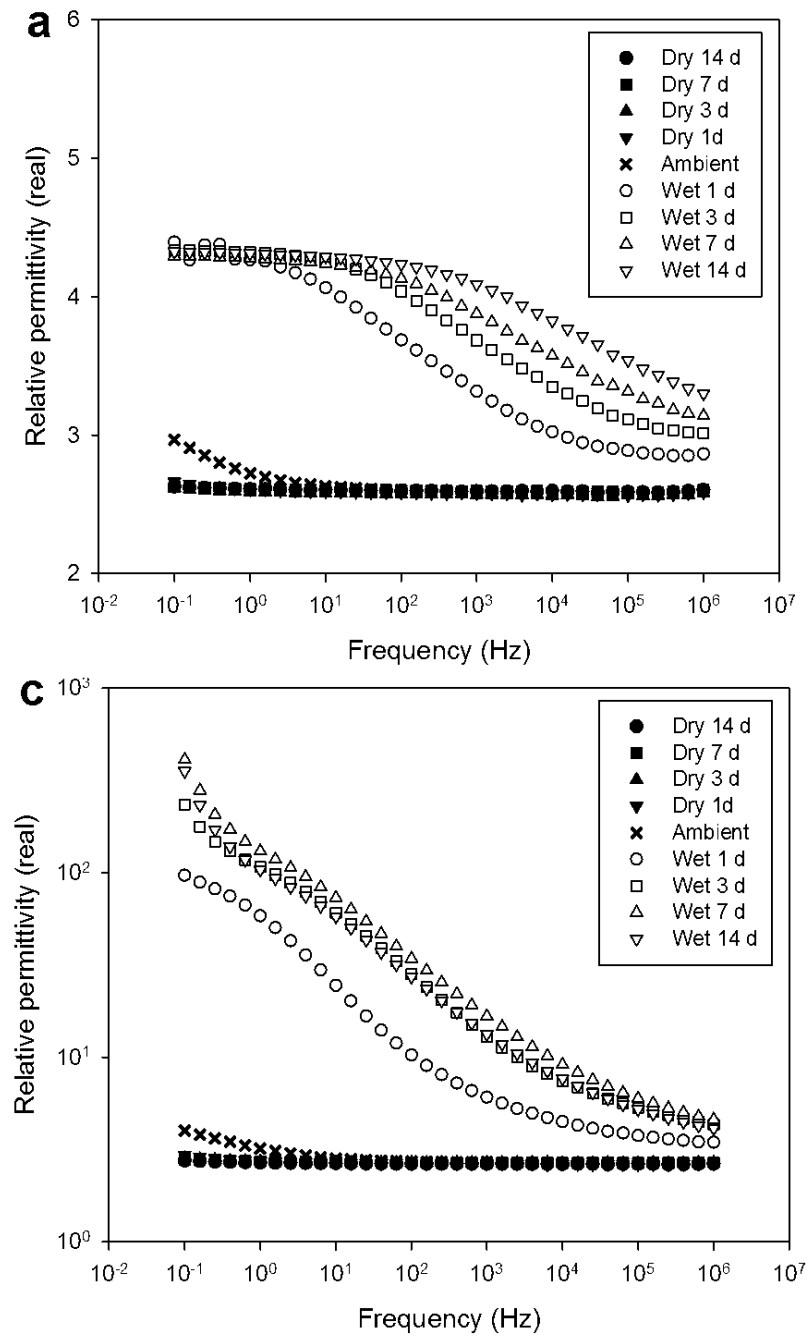

way associated with the nanoparticles themselves. Water immersion increases both $\varepsilon$ ' and $\varepsilon$ " to very high values at low frequencies, where a gradient close to -1 in the log-log plot of imaginary permittivity against frequency (Fig. 8d) implies electrical conductivity.

\section{E. Water Content and Electrical Conductivity}

Fig. 9a shows electrical conductivity values measured as a function of applied field after ambient conditioning, which demonstrates that all of the nanocomposites exhibit increased conductivity relative to the control sample, as observed elsewhere [17, 22]. However, the nano-silica and nano-silicon nitride-based composites show very different field dependencies; the conductivity of SiN05 and SiN10 are largely independent of applied field whereas the conductivity of SiO05 and SiO10 increases with applied field. A strong field dependence of conductivity in silica/epoxy composites has been reported previously [8] and is consistent with a field assisted Schottky injection process mediated by included water ions, which provide an additional ionic contribution to the steady state conduction current. The situation in the nanosilicon nitride-based systems is less clear, although in view of
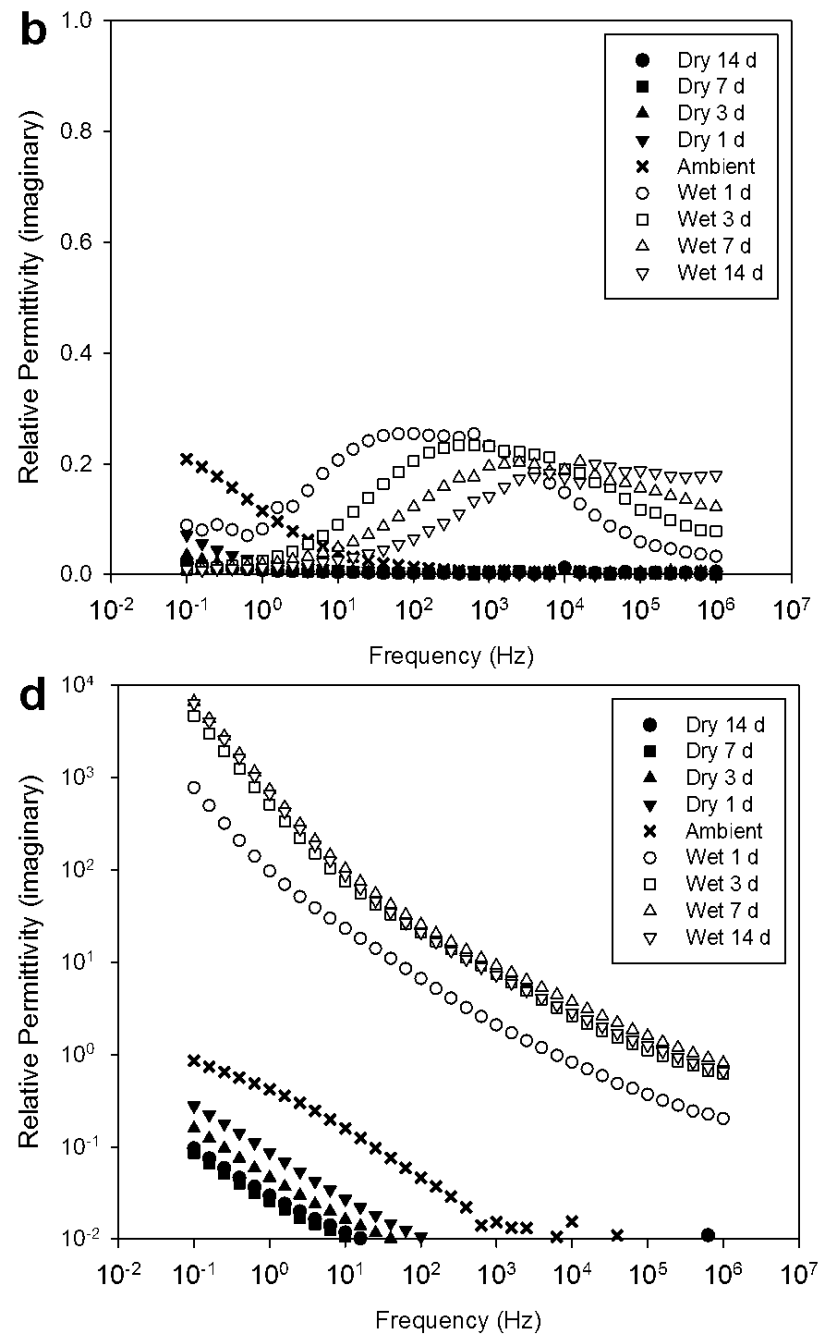

Fig. 8. Permittivity measurements; (a) SiN05 real (b) SiN05 imaginary, (c) SiN10 real, (d) SiN10, imaginary. 

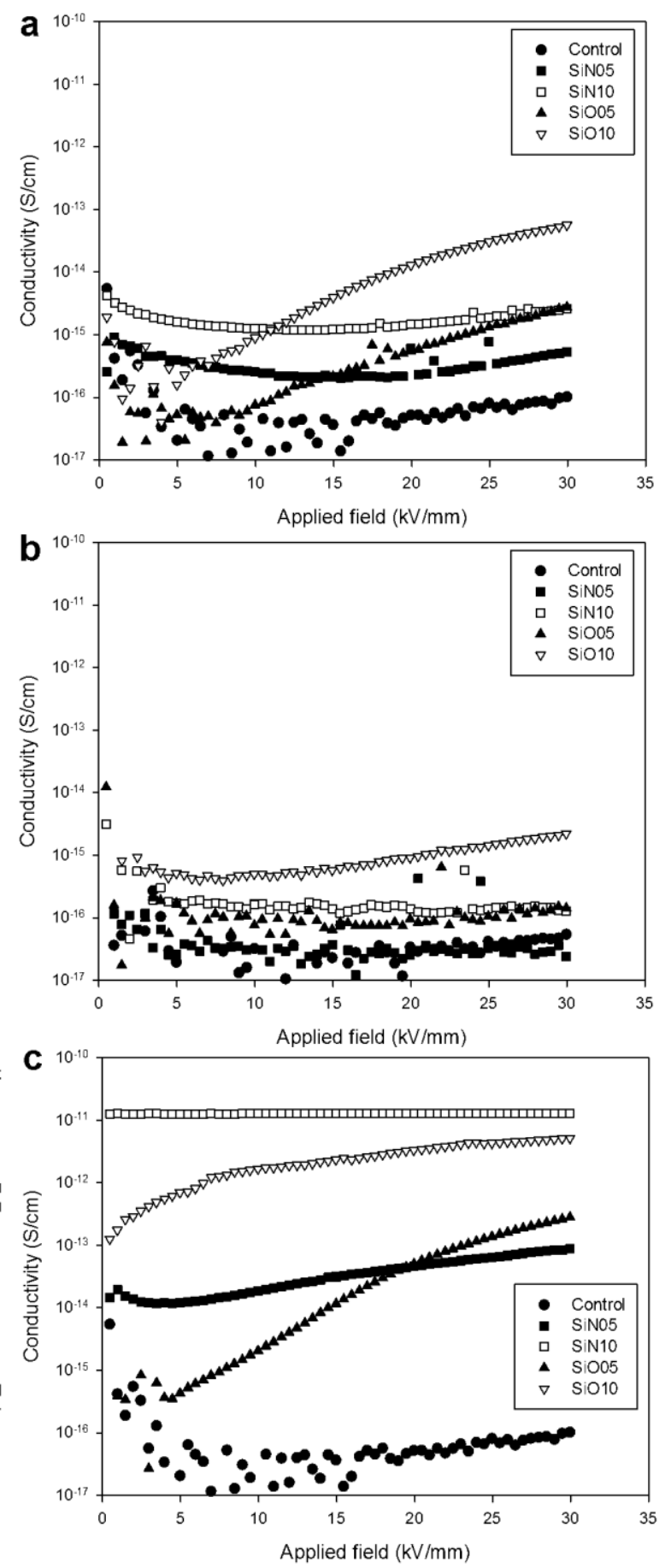

Fig. 9. Electrical conductivity measurements; (a) ambient conditioning (b) dry conditioning (c) wet conditioning.

the low water content, we suggest that in these systems the conduction current is mainly electronic in nature and, hence, may be space charge rather than field limited [8]. Regardless of the precise mechanisms involved, the data suggest that very different conduction mechanisms are operative in the two different types of nanocomposites. A comparison of the results shown with comparable data obtained from analogues containing functionalized nano-silica [22] indicates a significantly reduced conductivity in the systems considered here.

Conditioning in vacuum reduces the conductivity of the systems (Fig. 9b) to values approaching those of the control sample, which is close to the sensitivity limit of our apparatus. Only SiO10 shows any significant difference, which may be explained by the presence of the retained hydration layer discussed above [15]. Conversely, conditioning by immersion in water increases the electrical conductivity (Fig. 9c) of all except the unfilled control system. Also, the conductivity of $\mathrm{SiO} 05$ and SiO10 are strongly field dependent, whilst SiN05 has a weaker field dependence. SiN10 has a conductivity which is close to the maximum measurable value and exhibits no obvious field dependence.

\section{F. Simulation of Percolation}

It is clear from the preceding sections that the introduction of nanoparticles into a non-polar matrix polymer has a dramatic effect on the way in which the composite system interacts with the environment and that this can lead to major changes in dielectric properties. Also, it is evident that nanocomposites based upon nano-silica and nano-silicon nitride behave very differently, presumably because of variations in surface chemistry and particularly hydroxyl content. Conventionally, improvements in the properties of nanocomposites are associated with enhanced nanoparticle dispersion, but comparing the morphology of SiN10 (Fig. 2c) with that of SiO10 (Fig. 3b) indicates that the dispersion is very much better in SiN10, yet from Fig. 9c, it is clear that the behavior of this system as an electrical insulator can be markedly inferior. We propose that this anomalous behavior arises due to the formation of a percolating water network.

The volume filler fraction of SiN10 is $3 \%$ (assuming a filler density of $3.44 \mathrm{~g} / \mathrm{cm}^{3}$ and a polymer density of $0.95 \mathrm{~g} / \mathrm{cm}^{3}$ ), which is well below the threshold for percolation for conducting spheres in a non-conducting matrix [28]. However, numerical modelling calculations by other authors [15] have shown that it is possible to obtain a percolating network in such a system by introducing water shells of $\sim 60 \mathrm{~nm}$ thickness around each nanoparticle. To explore the relevance of such concepts to the unexpected behavior of SiN10 described above and to verify that no percolation occurs in SiN05, a numerical model was implemented in MATLAB. In this, a random distribution of the required number of $50 \mathrm{~nm}$ diameter (Fig. 2c) nanoparticles (calculated from the filler fraction) was assumed, which were not permitted to overlap. Each particle was then surrounded by a water shell, which was permitted to overlap with adjacent water shells. Assuming that the water occupies the free volume within the polymer matrix, which equates to $\sim 2 \%$ [29], and that the total water content is 0.4 and $0.7 \mathrm{wt} . \%$ (Fig. 6) for fully saturated SiN05 and SiN10 respectively, then the extent of each water shell was found to be $\sim 50 \mathrm{~nm}$, which is consistent with other work [15].

The model was run repeatedly and typical results are shown in Fig. 10 for a simulation within a cube of side $0.75 \mu \mathrm{m}$. In the model of SiN05 (Fig. 10a), percolation (defined as a complete water path between opposing faces of the model volume) was never achieved while, in SiN10 (Fig. 10b), percolation was always achieved. In the silica 
a

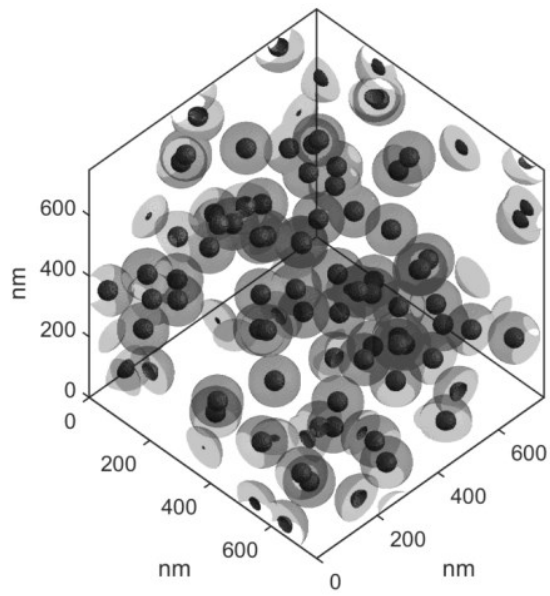

b

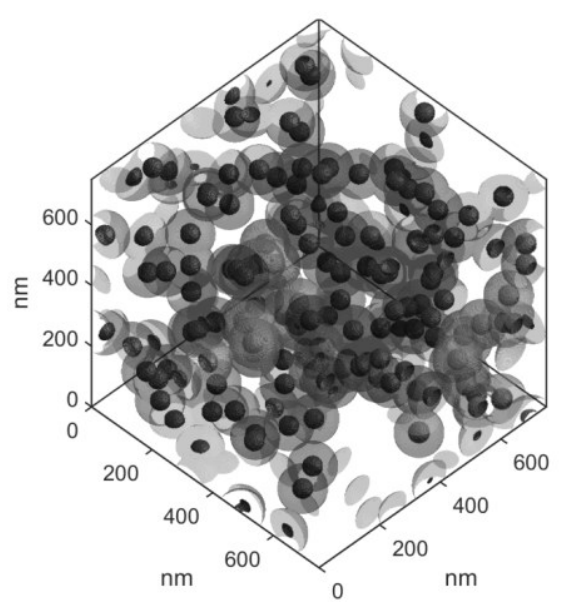

Fig. 10: Numerical modelling results, particles in black, water shells in mid grey, percolation path in dark grey; (a) SiN05, (b) SiN10.

nanocomposites, a percolating network is not formed, due most likely, to particle aggregation (see Fig. 3); aggregation allows water shells locally to overlap so reducing the overall volume fraction of the system occupied by water-containing interphase regions to below that required for percolation [15, $28]$.

\section{CONCLUSIONS}

Four nanocomposites, two containing nanosilica and two containing nano-silicon nitride were compared to an unfilled control sample. The effects of conditioning (dry, ambient or wet) were also explored. Examination of the structure of the various nanocomposites demonstrated that the nano-silicon nitride was uniformly dispersed, whereas obvious aggregations existed within the nano-silica-based systems. Conventional concepts concerning the fundamental processes by which the introduction of nanofillers serve to affect macroscopic properties is through interfacial interactions and, therefore, it would be expected that the systems based upon nano-silicon nitride would exhibit superior properties to those based upon nano-silica. However, this was not generally the case and, particularly after water immersion, a combination of accumulation of water at nano-silicon nitride surfaces and the close proximity of neighboring nanoparticles (i.e. good dispersion) in the SiN10 led to this system exhibiting a high electrical conductivity. A paradigm of nanodielectrics is that improved properties result from improved dispersion but, in comparing two systems with very different dispersion characteristics, we have shown that this is not always the case. Problems can emerge in well dispersed systems when the nanoparticles are spaced sufficiently closely that percolation effects dominate.

In this study we have therefore shown that the electrical properties of nano-composites are not dominated by nanoparticle dispersion and that circumstances exist whereby enhanced dispersion leads to inferior behavior. Here, this has been exemplified by the influence of water adsorbed at nanoparticle surfaces, which has a dramatic effect on a range of electrical parameters (permittivity, dielectric loss, electrical conduction). The sensitivity of macroscopic properties to included water - a parameter that is not generally considered may also provide an explanation for the different forms of behavior reported in the literature for apparently equivalent nanocomposite systems. Finally, water is ubiquitous in the environment. Consequently, from a practical engineering perspective, if the beneficial characteristics of nanodielectrics are ever to be reliably exploited technologically, then the ways in which this class of materials interact with environmental water need to be understood and controlled.

\section{REFERENCES}

[1] T. Tanaka, "Dielectric nanocomposites with insulating properties", IEEE Trans. Diel. Electr. Insul., vol. 12, no. 5, pp. 914-928, Oct. 2005.

[2] R. C. Smith, C. Liang, M. Landry, J. K. Nelson and L. S. Schadler, "The Mechanisms Leading to the Useful Electrical Properties of Polymer Nanodielectrics", IEEE Trans. Diel. and Electr. Insul., vol. 15, no. 1. pp. 187-196, Feb. 2008.

[3] M. G. Danikas, T. Tanaka, "Nanocomposites-A Review of Electrical Treeing and Breakdown", IEEE Electr. Insul. Mag., vol. 25, no. 4, pp. 19-25, Jul-Aug. 2009.

[4] S. Li, G. Yin, G. Chen, J. Li, S. Bai, L. Zhong, Y. Zhang, and Qingquan Lei, "Short-term Breakdown and Long-term Failure in Nanodielectrics: A Review", IEEE Trans. Diel. Electr. Insul., vol. 17, no. 5, pp. 15231535, Oct. 2010.

[5] A. Sami, M. F. Frechette, E. David and S. Savoie, "Water as a Digression Relative to the Dielectric Response in the Frequency Domain for Polymer Composites", In 2008 Ann. Rep. Conf. Electr. Insul. Diel. Phen., Quebec, Canada, 2008, pp. 501-504.

[6] M. G. Veena, N. M. Renukappa, J. M. Raj, C. Ranganathaiah, K. N. Shivakumar, "Characterization of Nanosilica-Filled Epoxy Composites for Electrical and Insulation Applications", J. Appl. Polym. Sci., vol. 121, no. 5, pp. 2752-2760, Sep. 2011.

[7] G. Iyer, R. S. Gorur, R. Richert, A. Krivda and L. E. Schmidt, "Dielectric Properties of Epoxy based Nanocomposites for High Voltage Insulation", IEEE Trans. Diel. Insul., vol. 18, no. 3, pp. 659- 666 , Jun. 2011.

[8] J. Castellon, H. N. Nguyen, S. Agnel, A. Toureille, M. Fréchette, S. Savoie, A. Krivda and L.E. Schmidt, "Electrical Properties Analysis of Micro and Nano Composite Epoxy Resin Materials", IEEE Trans. Diel. Electr. Insul., vol. 18, no. 3, pp. 651-658, Jun. 2011.

[9] J-J. Park, "Effect of Nanosilica on the Mechanical Properties and AC Electrical Breakdown Strength of Epoxy/Microsilica/Nanosilica Composite", Trans. Electr. Electron. Mater., vol. 13, no. 6, pp. 301-304, Dec. 2012.

[10] R. Kochetov, I.A. Tsekmes,T. Iizuka, K. Tatsumi, T. Tanaka, "The Effect of Nanosilica on the DC Breakdown Strength of Epoxy based Nanocomposites", In 2014 Ann. Rep. Conf. Electr. Insul. Diel. Phenom., Des Moines, USA, 2014, pp. 715-718.

[11] M. Roy, J. K. Nelson, R.K. MacCrone, L.S. Schadler, C.W. Reed, R. Keefe and W. Zenger, "Polymer Nanocomposite Dielectrics - The Role 
of the Interface", IEEE Trans. Diel. Electr. Insul., vol. 12, no. 4, pp. 629643, Aug. 2005.

[12] M. Roy, J. K. Nelson, R. K. MacCrone, L. S. Schadler ,"Candidate mechanisms controlling the electrical characteristics of silica/XLPE nanodielectrics", J. Mater. Sci., vol. 42, no. 11, pp. 3789-3799, Jun. 2007.

[13] K. Y. Lau, A. S. Vaughan, G. Chen, I. L. Hosier, A. F. Holt, "On the dielectric response of silica-based polyethylene nanocomposites", J. Phys. D: Appl. Phys., vol. 46, no. 9, Mar. 2013, Art. No. 095303.

[14] K. Y. Lau, A. S. Vaughan, G. Chen, I. L. Hosier, A. F. Holt, K. Y. Ching, "On the space charge and DC breakdown behavior of polyethylene/silica nanocomposites", IEEE Trans. Diel. Electr. Insul., vol. 21, no. 1, pp 340-351, Feb. 2014.

[15] L. Hui, L. S. Schadler, J. K. Nelson, "The Influence of Moisture on the Electrical Properties of Crosslinked Polyethylene/Silica Nanocomposites", IEEE Trans. Diel. Electr. Insul., vol. 20, no. 2, pp. $641-653$, Apr. 2013.

[16] L. Zhang, Y. Zhou, X. Cui, Y. Sha, T. H. Le, Q. Ye, J. Tian, "Effect of Nanoparticle Surface Modification on Breakdown and Space Charge Behavior of XLPE/SiO2 Nanocomposites", IEEE Trans. Diel. Electr. Insul. vol. 21, no. 4, pp. 1554-1564, Aug. 2014.

[17] S. L. Abd-El Messieh, N. N. Rozik, "Dielectric and Morphological Studies on Polyester/Nanosilica Fume Composites", J. Appl. Polym. Sci., vol. 122, no. 1, pp. 714-721, Oct. 2011.

[18] C. A. Grabowski, S. P. Fillery, N. M. Westing, C, Chi, J. S. Meth, M. F. Durstock, R. A. Vaia, "Dielectric Breakdown in Silica-Amorphous Polymer Nanocomposite Films: The Role of the Polymer Matrix", Appl. Mater. Interf. vol. 5, no. 12, pp. 5486-5492, Jun. 2013.

[19] D. M. Panaitescu, Z. Vuluga, P. V. Notingher, C. Nicolae, "The Effect of Poly[styrene-b-(ethylene-co-butylene)-b-styrene] on Dielectric, Thermal, and Morphological Characteristics of Polypropylene/Silica Nanocomposites", Polym. Engin. Sci., vol. 53, no. 10, pp. 2081-2092, Oct. 2013.

[20] M. Praeger, A. S. Vaughan, S. G. Swingler, "A dielectric spectroscopy study of the polystyrene/nanosilica model system”, In Proc. 2013 IEEE Int. Conf. Sol. Diel., Bologna, Italy, 2013, pp. 859-862.

[21] M. Praeger, A. S. Vaughan, S. G. Swingler, "The breakdown strength and localized structure of polystyrene as a function of nanosilica fill fraction”, In Proc. 2013 Int. Conf. Sol. Diel, IEEE, Bologna, Italy, 2013, pp. 863-866.

[22] I. L. Hosier, M. Praeger, A. F. Holt, A. S. Vaughan, S. G. Swingler, "Effect of water absorption on dielectric properties of nanosilica/polyethylene composites", In Proc. 2014 IEEE Conf. Electr. Insul. Diel. Phen., Des Moines, USA, 2014, pp.651-654.

[23] S. I. Raider, R. Flitsch, J. A. Aboaf and W. A. Pliskin, "Surface Oxidation of Silicon Nitride Films", J. Electrochem. Soc., vol. 123, no. 4, pp. 560-565, Apr. 1976.

[24] W. Zhou, C. Wang, T. Ai, K. Wud, F. Zhao, H. Gu, "A novel fiberreinforced polyethylene composite with added silicon nitride particles for enhanced thermal conductivity", Composites Part A: Appl. Sci. Manuf., vol. 40, no. 6-7, pp. 830 - 836, Jul. 2009.

[25] G. C. Xu, J. Wang, X. L. Ji, J. Y. Xiong, F. Li, "Effect of Nano-silicon Nitride on the Mechanical and Electric Properties of Polypropylene Nanocomposite", J. Comp. Mater., vol. 41, no. 18, pp. 2213-2223, Sep. 2007.

[26] R. H. Olley and D. C. Bassett, "An improved permanganic etchant for polyolefins", Polymer, vol. 23, no. 12, pp. 1707-1710, Nov. 1982.

[27] L. Huang, R. Zhan, Y. Lu, "Mechanical properties and crystallization behavior of polypropylene/nano-SiO2 composites", J. Reinf. Plast. Comp., vol. 25, no. 9, pp 1001-1012, Jun. 2006.

[28] S. Nakamura, K. Saito, G. Sawa, K. Kitagawa, "Percolation threshold of carbon black-polyethylene composites", Jap. J. Appl. Phys., vol. 36, no. 8, pp. 5163-5168, Aug. 1997.

[29] X. Zhou, L. Zhai, J. Du and R. Han, "Free volume changes in gamma irradiated polyethylene and polytetrafluorethylene", J. Mater. Sci. Technol., vol. 16, no. 3, pp. 302-304, May 2000.

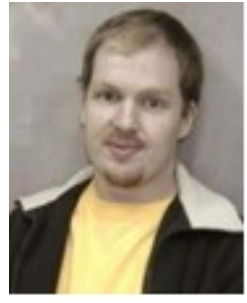

Ian Hosier received the B.Sc. degree in physics and the Ph.D. degree in polymer physics from The University of Reading, UK. He then went on with postdoctoral research at the same university, which involved collaborations with institutions in Germany and Japan. In 2001 he accepted a placement at Florida State University in the USA looking at atomic force microscopy of semi-crystalline polymer blends. In 2003 he returned to the UK to take a research post at the University of Southampton looking at the aging behavior of a variety of solid and liquid insulation materials. Research interests include dielectrics, ageing, microscopy and polymer morphology.

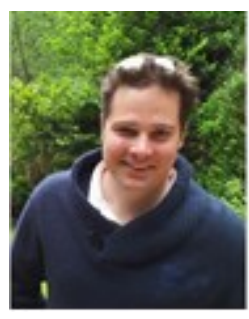

Matthew Praeger has an M.Phys degree in Physics with Laser Science and received a Ph.D for Laser Generation of X-rays; both were awarded by the University of Southampton. He subsequently worked at the Optoelectronics Research Centre on laser beam characterization but then shifted focus to applications, developing microfluidic and electrohydrodynamic devices. Since moving to the Electrical and Electronic Engineering group he has pursued interests in electrical phenomena such as dielectrophoresis and in nanocomposite materials for dielectric applications.

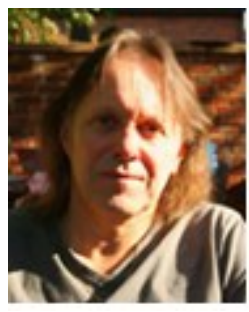

Alun Vaughan (SM'07) has a B.Sc. degree in chemical physics and a Ph.D. degree in polymer physics. After working at the UK's Central Electricity Research Laboratories and spending a period as an academic at The University of Reading, he is now Professor of Dielectric Materials and Head of the Electronics and Electrical Engineering research group at the University of Southampton. $\mathrm{He}$ is a former chair of The Dielectrics Group of the Institute of Physics, a Fellow of the Institute of Physics and a Fellow of the IET. In 2016 he presented the Eric O. Forster Memorial Lecture.

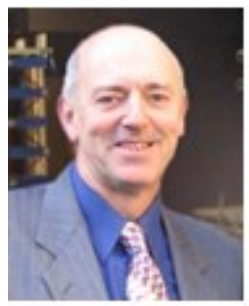

Steve Swingler received the B.A. and $\mathrm{Ph} . \mathrm{D}$. degrees in physics from the University of Lancaster. In 1976 he was appointed Pirelli Postdoctoral Research Fellow at Southampton University, investigating dielectrics for superconducting and extruded dc cables. He joined the Central Electricity Research Laboratories at Leatherhead in 1979 working mainly on novel cable systems and insulating materials. In 1990 he transferred to the National Grid Company, becoming Cables Manager and then Company Undergrounding Adviser. In 2003 he joined the School of Electronics \& Computer Science at Southampton University as Professor in Transmission Asset Engineering and retired in 2015. 